\title{
Na Terra do Metal: materialidades e epifanias estéticas do heavy metal numa fronteira amazônica
}

\author{
Talita Cristina Araújo Baena, Otacílio Amaral Filho
}

\section{Resumo}

Este artigo traz a análise das materialidades da banda de thrash metal Antcorpus. Vetorizadas por meio de tecnointerações observa-se que, em tais materialidades, há a emergência de epifanias estéticas de espaços fronteiriços da Amazônia. Estas, por sua vez, dão forma a uma poética de dissenso, na qual são enunciadas diferenças culturais e identitárias, contestadoras de uma Amazônia imaginada, desde o período colonial, como o "El Dourado" ou "o paraíso verde". Concluise que, além da evidência do cosmopolitismo, a sonoridade do heavy metal está atrelada a um regime estético de identificação que oferece possibilidades de visualidades àqueles que estão na fronteira, nas margens, e que, por conta disso, são invisibilizados em modos hegemônicos e tradicionais de representação.

\section{Palavras-Chave}

Heavy Metal. Materialidades.Visualidades.
Talita Baena | talita.baena@gmail.com Mestre em Ciências da Comunicação pelo Programa de PósGraduação em Comunicação, Cultura e Amazônia da Universidade Federal do Pará - UFPA. Jornalista da Coordenação de Comunicação da Universidade Federal do Oeste do Pará - UFOPA.

Otacílio Amaral Filho I otacilioamaralfilho@gmail.com Doutor pelo Programa de Pós-graduação em Desenvolvimento Sustentável do Trópico Úmido da Universidade Federal do Pará - UFPA. Professor do Programa de Pós-Graduação em Comunicação, Cultura e Amazônia da Universidade Federal do Pará - UFPA.

\section{Introdução}

0 protagonismo de jovens no espaço urbano tem materializado epifanias estéticas (GUMBRECHT, 2010, p. 140) do heavy metal que concretizam a emergência de cenas musicais em diversas partes do mundo ${ }^{1}$. No caso apresentado neste artigo, a cena musical ocorre fora de Belém (PA), cidade fortemente midiatizada como um celeiro de uma cena musical, na qual têm surgido novos expoentes de uma música popular brasileira em seus aspectos regionais. Longe, portanto, da retórica de autenticidade da cena musical de Belém, os jovens da cena urbana da cidade de Parauapebas, Sudeste do Estado, enunciam suas retóricas das margens e da diferença cultural por meio da poética do heavy metal.

Para descrever a poética da banda de thrash metal Antcorpus, analisamos duas materialidades dela: o primeiro EP, Chuva Ácida, e o primeiro álbum, Na Terra do Metal ${ }^{2}$. Além disso, resgatamos a história dos rituais de consumo do rock na cidade de Parauapebas (PA), com o objetivo de perceber a epifania 
estética do heavy metal a partir do consumo da música nesses rituais.

A banda, atualmente formada por Djair Oliveira (vocal), Johnny Santos (bateria), Francisco Pereira (baixo), André Guimarães (guitarra) e Anderson Albuquerque (guitarra), surgiu no ano de 2003, e foi por meio de um complexo sistema de midiatização e de tecnointerações em sites como Flogão, Orkut e MSN, que ela adentrou em outras cenas do rock em cidades como Imperatriz e São Luís, no Maranhão, e também na cidade de Gurupi, no estado do Tocantins, participando de pequenos festivais produzidos pelos sujeitos dessas cenas musicais. Essas interações e tecnointerações permitiram que a banda, na época, ainda sob influência de subgêneros como 0 newmetal e metalcore, se definesse pela estética do thrash metal oldschool ${ }^{3}$, para ilustrar os dissensos e a enunciação da diferença cultural contidas no espaço intersticial da cultura.

Destaca-se aqui que as materialidades comunicacionais desta enunciação da diferença estão vinculadas ao que Jacques Rancierè (2005) define como 0 regime estético das artes, e segundo 0 filósofo é aquele regime que

\begin{abstract}
Propriamente identifica a arte no singular e desobriga essa arte de toda e qualquer regra específica, de toda hierarquia de temas, gêneros e artes. Mas, ao fazê-lo, ele implode a barreira mimética que distinguia as maneiras de fazer arte das outras maneiras de fazer e separava suas regras da ordem das ocupações sociais. (RANCIERÈ, 2005, p. 33-34).
\end{abstract}

Neste regime, observa-se que a ação regida pelo estatuto, ou a política de estesia dos que produzem a cena dos "sem parte", não insere os sujeitos da cena em uma determinada comunidade musical tradicional já existente. Na verdade, a ação redefine a vida dos sem parte por meio de "um processo que mistura a expressão de um dano (figura da divisão) e a verificação da igualdade" (MARQUES, 2013, p. 244).

É, portanto, o predomínio desta figura da divisão que, ao enunciar sua diferença cultural, promove epifanias estéticas do heavy metal no espaço da fronteira, o que constatamos nas materialidades da banda Antcorpus. Sobre a noção de epifania na

No documentário Metal Evolution (Episódio 1), o antropólogo canadense Sam Dunnper percorre 40 cidades em 12 países, buscando as raízes sonoras do heavy metal. Uma das cidades visitadas é Birmingham, na Inglaterra, berço da primeira banda de heavy metal, Black Sabath (WEINSTEIN, 2000).

As faixas podem ser ouvidas no link https://soundcloud.com/antcorpusthrash.

Diferentemente do seu precursor, o heavy metal, ou do seu contemporâneo, o punk, a estética do thrash old school, isto é, thrash metal oitentista, é marcada por riffs agressivos, bateria de pedal duplo e vocais agudos. As bandas Anthrax, Megadeth, Metallica e Slayer popularizaram o gênero no começo da década de 1980. Também podem ser citadas como bandas do gênero: Exodus, Testament, Sodom, Kreator, Overkill, Destruction e a brasileira Sepultura. 
experiência estética, Gumbrecht (2010) afirma:

Com "epifania" não quero dizer, de novo, simultaneidade, tensão e oscilação entre sentido e presença; quero dizer, sobretudo, a sensação, citada e teorizada por Jean-Luc Nancy, de que não conseguimos agarrar os efeitos de presença, de que eles - e, com eles, a simultaneidade da presença e do sentido - são efêmeros. De modo mais preciso: sob o título "epifania" pretendo comentar três características que moldam a maneira como se apresenta diante de nós a tensão entre presença e sentido: pretendo comentar a impressão de que a tensão entre presença e sentido, quando ocorre, surge do nada; a emergência dessa tensão como tendo uma articulação espacial; a possibilidade de descrever sua temporalidade como um "evento". (GUMBRECHT, 2010, p. 140).

Dessa forma, a noção de epifania estética é estruturadora para a compreensão dos modos de presentificação da experiência da música nos espaços da urbe.

\section{A Epifania do heavy metal no espaço da fronteira}

Para 0 entendimento da poética da banda é importante ressaltar que a Antcorpus, por meio de suas imagens sonoras e visuais, nos apresenta alegorias da diferença cultural decorrente da migração pós-colonial que ocorre na região desde a década de 1970, quando foram descobertas jazidas de minério de ferro na Serra dos Carajás.
Esse processo, denominado em diversas

literaturas como um processo de fronteirização do espaço amazônico, foi estimulado por uma propaganda governamental inspirada pelos mitos do Eldorado e do progress $0^{4}$. Em consequência, essas migrações possibilitaram a criação de vilarejos que posteriormente se tornaram pequenas cidades no entorno da Serra dos Carajás, Estrada de Ferro Carajás e Serra Pelada, durante a década de 1980. Marcadas por um processo de ocupação diferente de outras regiões do estado, essas populações possuem práticas culturais que não são, em certa medida, similares às de outras regiões do estado. A noção e a enunciação da diferença produziram nessas populações a possibilidade de contestação cultural, que recentemente culminou na reivindicação de separação e criação de outro estado, o estado do Carajás.

Castro (2011, p. 214) diz que a

$$
\begin{aligned}
& \text { "Amazônia não é um lugar a priori, mas sim } \\
& \text { um lugar inventado no seu uso. (...). A Ama- } \\
& \text { zônia dos artistas não é, necessariamente, } \\
& \text { a mesma das populações tradicionais nem } \\
& \text { essas populações correspondem necessaria- } \\
& \text { mente ao que os artistas idealizam como tipos } \\
& \text { humanos emblemáticos." }
\end{aligned}
$$

Por esse ângulo, pode-se notar que, já no âmbito da música, os jovens migrantes ou filhos de 
migrantes também enunciam sua diferença por meio de uma produção cultural e performática a partir do consumo, apropriação e reprodução da música popular massiva, inventando o seu próprio lugar como forma de expressão, que se articula com 0 ambiente midiático também como lugar de interação e expressividade pela ocupação do espaço espetacular como forma de demarcação da identidade na moderna tradição amazônica.

Assim, partindo de interações e tecnointerações, essas últimas possibilitadas primeiramente pela prática de escuta do rádio e posteriormente pelo uso da Internet, jovens da cidade de Parauapebas protagonizam no espaço da urbe e da cultura, já há algum tempo, rituais de consumo da música ao vivo denominada por eles próprios de "rockadas", que, por meio da música e de outras materialidades comunicacionais e da cultura, promovem a visibilidade de uma diferença cultural, advinda desta migração pós-colonial. Dessa forma, como nos lembra Bhabha, a enunciação dessa diferença cultural objetiva

rearticular a soma do conhecimento a partir da perspectiva da posição de significação da minoria, que resiste à totalização - a repetição que não retornará como 0 mesmo, 0 menos-na-origem que resulta em estratégias políticas e discursivas nas quais acrescentar não soma, mas serve para perturbar o cálculo do poder e saber, produzindo outros espaços de significação subalterna (BHABHA, 1998, p. 228).

Neste momento em que a relação música, identidade e cidade se inter-relacionam, Janotti Júnior (2012) argumenta que, no consumo globalizado da música, não é mais possivel isolar as inter-relações entre música e identidade em espaços engessados, o que permite perceber que nas cenas se afirmam identidades nas constantes negociações entre afirmações cosmopolitas (conexão com expressões musicais que circulam em lugares distintos do planeta através da internet e outros meios) e a forma como as mesmas expressões musicais se materializam em diferentes espaços urbanos (JANOTTI JÚNIOR, 2012, p. 116).

Em Parauapebas, portanto, a partir dos rituais de consumo da música ao vivo, é possível perceber, além da materialização da música popular massiva no espaço da urbe, processos de identificação cultural e 0 início da autonomização da produção simbólica da cultura, com o registro sonoro das músicas autorais. E dessa forma a representação da cidade se constitui pela cena midiática que funciona na lógica espetacular, acionando os dispositivos da visualidade e visibilidade e pela quebra da intimidade e requisição de um sujeito público como identidade individual que ao mesmo tempo se projeta a nível global como diferença. A cena midiática, por sua vez, organiza-se tanto pelo poder de publicizar como pelo poder de representar. Pela lógica política, essa ordem midiática se dá pela interatividade e pelo compartilhamento da informação como mercadoria e como acontecimento midiático na reprodução da realidade.

É certo que esses registros vêm seguindo padrões hegemônicos da indústria da música, pois ao estabelecer estratégias de agenciamento 
relacionadas às gramáticas de produção já consolidadas pela indústria fonográfica, pretendem o reconhecimento da experiência sonora como sendo a mesma experiência vivida na escuta do indie rock ou do heavy metal oldschool, por exemplo. No entanto, mesmo com tal reprodução, há casos em que a experiência musical, à medida que suas produções convertem signos da urbe em experiência estética, produz uma imagem sonora e visual que tensiona e questiona aquela identificação cultural única, construída para fins políticos ou mercadológicos, como ocorre com a experiência sonora do projeto Terruá Pará (BAENA, 2013).

Voltando aos rituais do consumo da música ao vivo, a Antcorpus, junto com outras bandas locais como a Dracma contra Dracma, começou a formar público promovendo os próprios espaços para a apresentação e o consumo do heavy metal. Cai e Pira Rock (2006), Distorção Rock Day e Rockaos (2008) (Fig. 1 e 2) foram as primeiras rockadas organizadas pelo grupo, o que não quer dizer que foram os primeiros shows de rock da cidade. Eles já ocorriam desde a década de 1990, mas é com o Cai e Pira Rock que, como protesto ao Metal Rock, evento que vetou a participação de bandas locais, que se começa a perceber 0 protagonismo e a articulação desses jovens no espaço da cultura.

Neste momento, é possível perceber o surgimento de um contexto que pode ser caracterizado como uma cena musical do rock em Parauapebas, a epifania da cena. Isso porque as bandas começam um processo de especialização da performance ao vivo; no entanto, estas performances ainda pertenciam a uma esfera de atividade criativa da cultura (AMARAL FILHO, 2008), sem a força de vinculação enquanto mercadoria e mercado.

E este processo de especialização, que de certa forma intensifica a epifania da cena musical na região, torna-se evidente com a criação, em 2009, do extinto Cafofo Rock Bar. Este espaço, de propriedade do vocalista da Antcorpus, Djair Oliveira, permitiu a criação do coletivo Cafofo, que em 2010 promoveu o Festival Pebas Rock, projeto que naquele ano tinha sido aprovado pelo edital Microprojetos da Amazônia Legal do Ministério da Cultura (MINC). Com o apoio e a marca do MINC, o festival ganhou a visibilidade da mídia paraense, com matéria publicada no jornal Diário do Pará, no dia 10 de dezembro de 2010 (Fig. 3).

Logo no ano seguinte ao da realização do festival, a experiência do thrash metal do limiar da cena do rock paraense entraria no circuito de festivais da cidade de Belém, capital do estado, quando a Se Rasgum Produções, produtora de eventos culturais da cidade de Belém, capital do estado, realizou no mês de julho de 2011, na cidade de Marabá, a seletiva do Festival Se Rasgum (Fig. 4). A banda instrumental Pirucaba Jazz de Marabá e a banda Antcorpus foram selecionadas e tocaram no festival que ocorreu em Belém, no mês de dezembro daquele ano. 


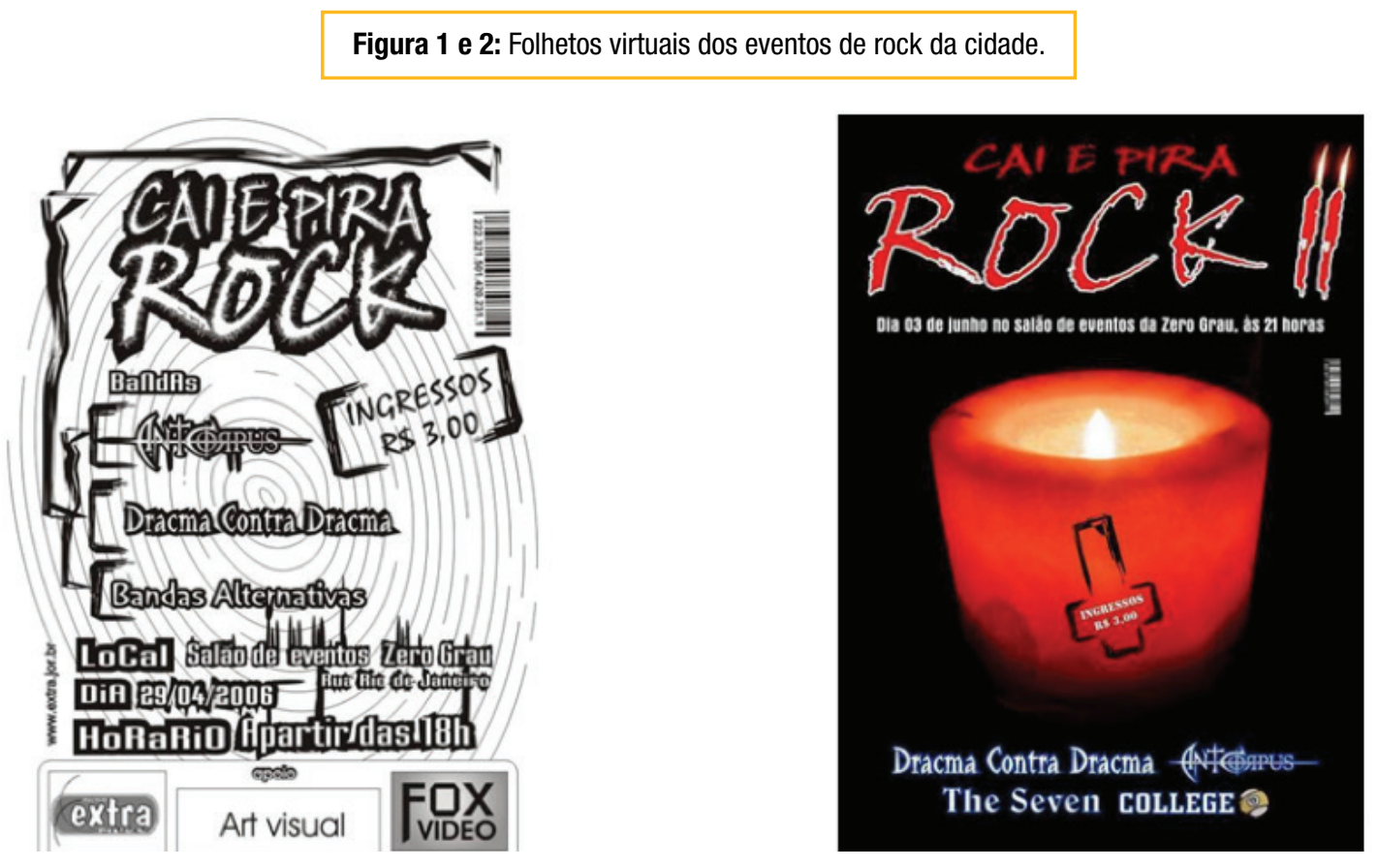

Tal efeito de presença e visibilidade permite pensar, seguindo a perspectiva de Janotti Júnior (2012), que a cena do rock de Parauapebas, mesmo distante dos grandes centros urbanos, articula-se com outras cenas musicais, sejam elas locais, translocais ou virtuais, pois, como argumenta 0 autor,

Uma cena de heavy metal local está conectada aos circuitos nacional e global, bem como aos aspectos virtuais de sua circulação nos meios digitais. Assim, podemos imaginar que shows e festivais de música são partes de uma rede cultural, econômica e afetiva que se afirma tanto nos espaços locais, quanto em nacionais e internacionais. Essa compreensão permite perceber o papel fundamental que as cidades exercem como espaços dinâmicos para a realização de várias práticas culturais conectadas ao consumo da música. Afinal, mesmo práticas de escuta individuais pressupõem relações com o corpo do ouvinte e sua presentificação em um determinado espaço (JANOTTI JÚNIOR, 2012, p. 117-118).
Outra ação do protagonismo e efeito de presença da Antcorpus é a tática da banda de reunir em single as músicas que já haviam sido gravadas em estúdio caseiro e publicadas em sites como MySpace e PalcoMP3.

O single Chuva Ácida (2011) e o CD Na terra do metal reuniram as músicas "Chuva Ácida", "Artérias pobres", "Homicida Nuclear", "Metal e Violência". São por meio delas que diferença cultural é enunciada, formando uma estética da diferença e do dissenso.

\section{Imagens sonoras e visuais da poética da diferença}

Apesar de as inúmeras composições musicais em toda a Amazônia paraense revelarem gramáticas de reconhecimento, cujos efeitos 
Figura 3: Notícia do Festival Pebas Rock 2010 no site Diário do Pará.

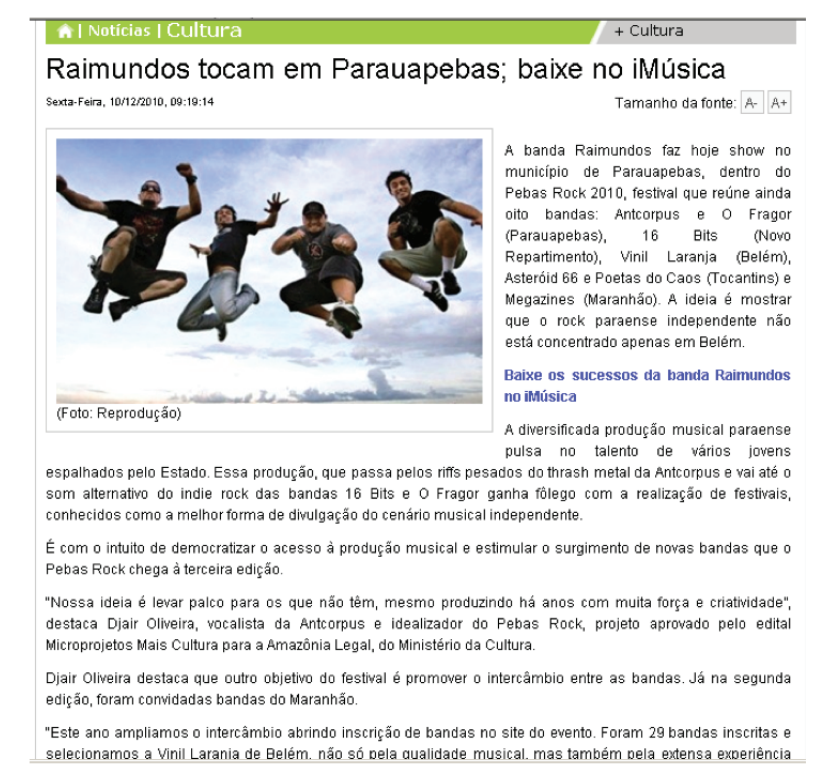

favorecem a política de identidade cultural de grupos artísticos hegemônicos, em cenas ou comunidades musicais dos espaços culturais da fronteira, por exemplo, observa-se uma poética em que imagens alegóricas revelam outras experiências estéticas, já nem tão harmônicas, entre o homem e a natureza.

0 primeiro álbum da banda Antcorpus, Chuva Ácida, é representativo neste sentido. Assimilando os códigos e aspectos que envolvem as gramáticas de produção e reconhecimento do heavy metal, a banda resignifica a história da região adotando dimensões e aspectos genéricos do heavy metal. Segundo Deena Weinsten (apud CARDOSO FILHO, 2008) são três as dimensões de aspectos genéricos do heavy metal.
A dimensão sonora é composta por elementos como a altura do som, os solos de guitarra, ritmo, tactilidade da música e pelos vocais. A dimensão visual engloba roupas, fotos, logos das bandas, e encartes dos álbuns além de suas cores dominantes. Por fim sua dimensão verbal é constituída pelos nomes das bandas, nomes dos álbuns e títulos das canções e das letras. (CARDOSO FILHO, 2008, p. 24).

Além dessas dimensões genéricas do heavy metal, Janotti Júnior (2013) ${ }^{5}$, observando as apropriações locais do heavy metal, diz que nele ainda existe uma dimensão que permite aos sujeitos locais inserir outras epifanias estéticas, próprias de cada local onde o heavy metal é produzido.

Foi preenchendo esta quarta dimensão do heavy metal que a banda Antcorpus fez toda a produção do primeiro single, com músicas gravadas em 
Figura 4: Antcorpus na Seletiva do Festival Se Rasgum 2011, em Marabá. Foto: Talita Baena .

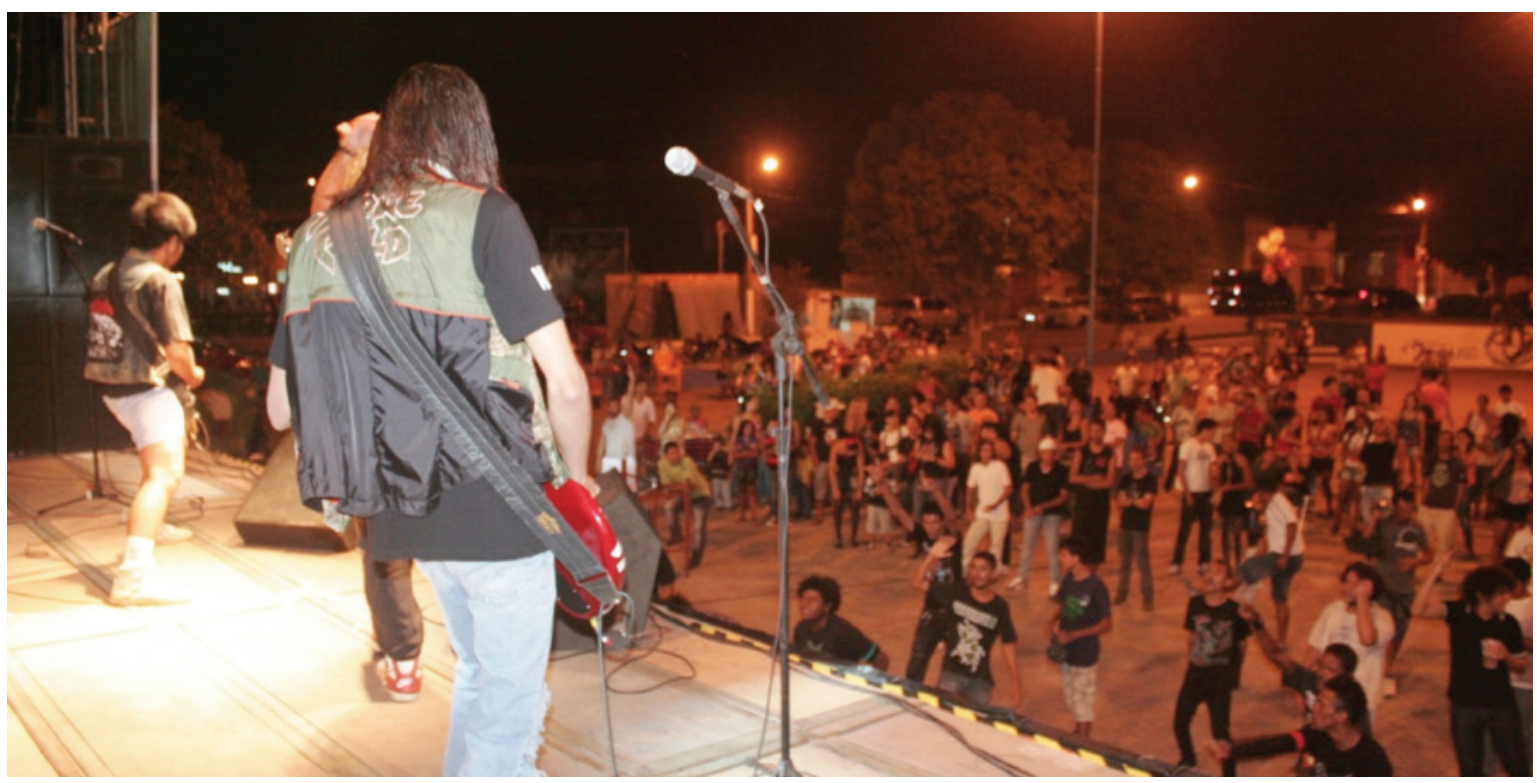

estúdio caseiro. Já a arte gráfica da capa (Fig. 5)

foi produzida pelo próprio vocalista da banda e

refere-se à prática de tortura ocorrida durante a guerrilha do Araguaia.

Para entender a alusão feita pela banda, primeiramente, lembramos que a Guerrilha do Araguaia ocorreu entre os anos de 1972 a 1975, e como ocorreu bem próximo à região de Carajás, a violência da guerrilha faz parte do imaginário dos que vivem nas regiões Sul e Sudeste do estado do Pará. Mas além deste imaginário, um militar repressor da guerrilha, Sebastião Curió, residiu durante anos no município vizinho, Curionópolis, onde está localizado o vilarejo denominado Serra Pelada, local conhecido na década de 1980 como grande formigueiro humano, por causa da exploração desordenada do ouro.
Voltando à análise da capa, já em um plano metafórico, os algozes não são apenas os militares da guerrilha, são também o fazendeiro, a multinacional e a velocidade de exploração do capital na região.

Outra figura retórica metafórica é a imagem do suor do torturado. Ela faz referência ao suor do trabalhador rural ou da exploração mineral e, por um efeito de hipérbole, ou seja, buscando um efeito de excesso ou exagero, torna-se a "Chuva Ácida”, que como sugere a letra da música, transcrita abaixo, deve provocar a destruição da nação, com piedade aos gregos, quer dizer, piedade aos migrantes que vivem na região.

\section{CHUVA ÁCIDA}

Antcorpus 
Figura 5: Capa do $1^{\circ}$ single. Foi produzida pelo vocalista da banda, Djair Oliveira.

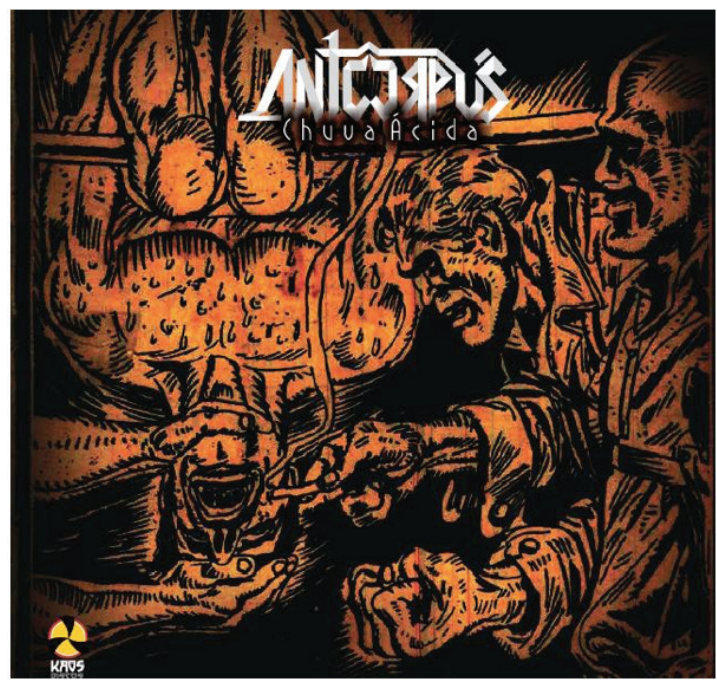

Quero destruição

E aos gregos, piedade

Inferno de nação

Inferno

Críticas destruição

Infecção interior

Na trilha chacina

Inferno

Chuva ácida

Chuva ácida

Chuva ácida

Chuva ácida

Quero destruição

E aos gregos, piedade

Inferno de nação

Inferno

Críticas destruição

Infecção interior

Na trilha chacina

Inferno
Mais uma vez, para a produção de sentido da diferença cultural, a modalidade do dizer da poética da Antcorpus recorre à metáfora "aos gregos" para fazer referência ao trabalhador da diáspora, da mão de obra migrante e barata que percorre os ciclos dos projetos governamentais na Amazônia, desde o ciclo do ouro de Serra Pelada, passando pela construção da Hidrelétrica de Tucuruí, construção da Ferrovia Carajás, o Projeto Ferro Carajás e mais recente, a construção da Hidrelétrica de Belo Monte. Dessa forma, podemos dizer que, enquanto os projetos políticos de identidade revelam a posição nativista ancorada no discurso colonial da Amazônia metrópole, o Antcorpus revela a Amazônia real convertida pelo pós-colonial.

Os enunciados como "destruição", "inferno", "chacina", e "ácida" são utilizados como estratégia para se chegar à poética do thrash metal. E é 
por meio dessa poética que a composição sonora e visual de "Chuva Ácida" transforma os fatos históricos de violência, ocorridos na região de Carajás, em experiência estética para os ouvidos já iniciados nesta experiência. Dessa forma, como disse o vocalista Djair Oliveira (BAENA, 2013), a expressão "chuva ácida"

é a representação do suor ácido dos trabalhadores imigrantes. É o suor derramado em função do trabalho pesado. "Aos gregos" refere-se aos imigrantes, então Chuva Ácida é a destruição com piedade aos "gregos" (migrantes) que sofrem e são eles que fazem o verdadeiro trabaIho. (AUTOR, 2014)

0 consumo e a apropriação da música popular massiva e o ethos transformado pela técnica e tecnocultura, na poética da Antcorpus, tornamse insumo poético, o que revela o quanto há de tensão no consumo cultural no contexto contemporâneo, pois a retórica da diferença na poética de Chuva Ácida também faz referência à disputa e às dificuldades enfrentadas nas margens do espaço da cultura. Assim, como afirmam

Fortuna e Silva (2002),

São várias as dificuldades que uma estratégia de desenvolvimento e modernização urbanos com base nos recursos da atividade cultural pode enfrentar. Desde logo, esses problemas decorrem da própria natureza da cultura que, ao mesmo tempo que se urbanizou, se foi globalizando, desterritorializou-se e projectou-se num plano cosmopolita (FORTUNA; SILVA, 2002).
Contudo, diferente de como afirmam Fortuna e

Silva (2002) de que em um plano cosmopolita, "as referências e os atores, as linguagens e os seus significados surgem cada vez mais abstratizados e referidos a universos que sendo compósitos suplantam largamente as dimensões localizadas do seu sentido", as imagens sonoras e visuais da produção cultural da banda Antcorpus demonstram a complexidade da experiência cosmopolita, pois ao mesmo tempo em que esse consumo indica uma mundialização de fluxos de bens simbólicos, também observamos a apropriação de linguagens e tecnologias que pluralizam as expressões culturais de um território, mesmo que seja a contrapelo de projetos de identidade.

É, portanto, a esse sentido de evanescência da experiência tradicional, própria da experiência dos que migram, que vivem nas margens e fronteiras do terceiro espaço, 0 da cultura, que o substantivo "destruição" de "Chuva Ácida" pretende nos remeter.

Ainda partindo desta experiência de migração, as imagens sonoras e visuais da violência no processo de ocupação territorial recente da região são retomadas na letra de "Na terra do metal". 0 impacto cultural do capitalismo produtivo, típico da atividade mineral, e também os inúmeros episódios de violência na região 
despontam na letra e na arte gráfica do segundo trabalho da banda (Fig. 6), que leva o mesmo nome da faixa principal.

\section{NA TERRA DO METAL}

Antcorpus

Na terra do metal

0 extermínio é animal

Da besta de ferro andante

Em sua parada final

Araguaia ${ }^{6}$, destruição

Guerrilheiros, aniquilação

Eldorado, perseguição

Morte, extermínio e dor

Na terra do metal

0 extermínio e animal

Da besta de ferro andante

Em sua parada final

Onde há fogo, agonia e clamor

Onde há ódio desgraça e terror

Pedidos de Clemência, thrash metal

thrash, thrash metal

thrash, thrash metal

thrash, thrash metal

thrash, thrash metal

Na letra, a metáfora "Na terra do metal" e a

hipérbole "o extermínio é animal" referem-

se à exclusão social percebida na cidade de

Parauapebas, onde está localizada a maior mina de ferro a céu aberto do mundo, mas como em outras cidades brasileiras, a irracionalidade contida nos bairros, em situação de risco social, não inclusivos e empobrecidos, revela-se bem diferente do imaginário do Eldorado e do progresso que impulsiona a migração para a cidade.

Outro elemento determinante na história e na vida dos que vivem na cidade de Parauapebas é o trem que transporta passageiros, mas, principalmente, as toneladas de minério de ferro de Carajás até o Porto de Itaqui, no Maranhão. É por meio da prosopopeia "da besta de ferro andante" que 0 trem recebe característica humana, 0 andar, mas também a denominação diabólica.

Aqui a influência da estética surrealista é evidente. E o forte apelo metafórico da capa do álbum "Na terra do metal" traz o migrante transformado pela violência da ocupação da região, sobretudo com as consequências dos impactos socioambientais decorrentes da construção da ferrovia Ferro Carajás. Sobrevivente de várias histórias de revolta e oposição ao poder opressor que se materializa na ferrovia, o migrante alegórico também faz referência à ocupação dos trilhos pelo movimento dos sem-terra e também pelo movimento dos garimpeiros de Serra Pelada, no Abril Vermelho do ano de 2009, ocorrido em protesto contra a atuação da mineradora Vale. É importante destacar que a narrativa do protesto da diferença cultural, de oposição ao mito do Eldorado e do progresso, acaba fazendo parte do imaginário desta Amazônia das Margens, a Amazônia da Fronteira, por assim dizer, pois para o vocalista da Antcorpus, a arte gráfica da capa do CD e a letra "Na terra do metal" remetem à 
Figura 6: Capa do CD “Na Terra do Metal”, também produzida pelo vocalista da banda.

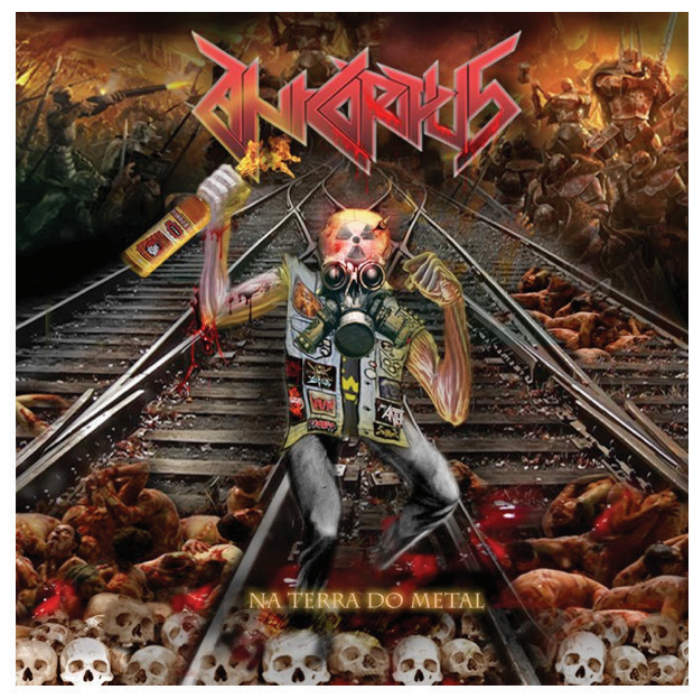

força da natureza em que só o mais forte sobrevive, tendo como plano de fundo a linha de ferro Carajás, e o extermínio e massacre de ativistas que lutam por reforma agrária e inclusão social no sudeste do Pará. De forma caricata o trem, a besta de ferro andante que em sua parada final, Parauapebas, deixa todos os dias centenas de imigrantes vindos do maranhão, em busca de trabalho e aqui eles se tornam ativistas da reforma agrária ou guerrilheiros de lutas partidárias e políticas. (Djair Oliveira, em entrevista concedida a Talita Baena).

0 que esta leitura dos tensionamentos entre produção de sentido e de produção de presença da diferença cultural percebida na obra da banda Antcorpus nos revela é como a música tem sido suporte para expressões artísticas que surgem a partir da experiência vivida na própria urbe. No caso da poética da Antcorpus aqui analisada, a problemática do crescimento desordenado das cidades amazônicas, que vivem a implantação de grandes projetos, evidencia a crítica a um processo que:
Desde a industrialização que as cidades não param de crescer e de se multiplicar. Tal crescimento, feito a custa do gradual esvaziamento sociocultural dos centros históricos das cidades e 0 alargamento das suas periferias e subúrbios, arrastou consigo renovados receios sobre a virtude da vida e da cultura urbana (Short, 1991; Arantes 1997). Os centros das cidades, em vez de traduzirem, de modo permanente, a heterogeneidade e a diversidade da cidade, tornaram-se socialmente mais homogêneos e segregados ou foram convertidos em lugares de visitação e cerimonial, mais ou menos regulares, de turistas e de residente suburbanos (Chaney, 1993). 0 desenrolar dramático da vida urbana tem vindo a ficar para trás e 0 espaço público urbano tradicional, lugar de ações e interações significantes, apresenta sinais de retração e crise. (FORTUNA; SILVA, 2002, p. 424).

Dessa forma, no espaço intersticial nas regiões

fronteiriças da Amazônia, a apropriação local do rock tem possibilitado a produção de sentido e de presença da diferença cultural inerentes a essas localidades. Tal diferença cultural, estimulada, mostrada, em certa medida, por processos 
de cosmopolitismo e de figuras de retóricas metafóricas e hiperbólicas, tem como suporte a música, que circula imagens sonoras e visuais da diferença cultural em tecnointerações. São elas que vetorizam formas culturais de um novo ethos, que, ao mesmo tempo em que surge a partir da técnica e da tecnocultura, questiona seus mitos de progresso, mas também questiona 0 mito do Eldorado Amazônico.

\section{Conclusão}

$\mathrm{Na}$ análise das materialidades da banda Antcorpus, percebe-se a epifania das estéticas do heavy metal, com dimensões locais de uma fronteira amazônica. Além da evidência do cosmopolitismo, a sonoridade do heavy metal está atrelada a um regime estético de identificação que oferece possibilidades de visualidades àqueles que estão na fronteira, nas margens, e que são invisibilizados pela produção oficial hegemônica e tradicional de representação e visibilizados na ordem não hegemônica dos espaços criados pelo discurso pós-colonial, cuja evidência maior é a diferença.

A união do protagonismo, que se dá a partir da enunciação da diferença cultural, com a publicização por meio de tecnointerações, que faz circular na rede virtual as imagens gráficas e sonoras da produção da banda, forma um conjunto de normas do sentir e do perceber que configuram uma política de estesia, mas que nesta lógica própria da cultura fazem emergir novas formas culturais que evidenciam outras espacialidades, não mais ligadas a uma ideia de identidade fixa ao contexto da moderna tradição amazônica como produto, mas na forma recortada das culturas como espetacularidades próprias da indústria do entretenimento.

Além disso, as figuras retóricas metafóricas e hiperbólicas têm como suporte a música, que circula em tecnointerações nas quais um ethos tecnocultural é vetorizado. Essas formas e expressões artísticas e culturais, ao mesmo tempo em que surgem a partir da técnica e da tecnocultura, questionam mitos.

Assim, o conjunto dessas articulações, além de tornar evidente a globalização dessas práticas culturais emergentes, ainda revela modos de interação social e política, experiências estéticas e formas de comunicação que identificamos como tecnointerações, que promovem a circulação da produção musical por meio de suas imagens visuais, sonoras e de diferença, visibilizando poéticas de dissenso.

Dessa forma, concluímos que as materialidades da banda Antcorpus demonstram que as expressões criativas por meio da música dão significado à experiência vivida na cidade, como se fosse um lugar identitário. Demonstram também um novo estatuto das artes em nossa sociedade, vetorizando necessidades políticas e estéticas, ao questionar hegemonias diluídas no discurso global da diferença. 


\section{Referências}

AMARAL FILHO, Otacílio. Marca Amazônia: uma promessa publicitária para fidelização de consumidores nos mercados globais. Belém: UFPA. 2008, 413p. Tese (Doutorado) - Universidade Federal do Pará, Núcleo de Altos Estudos Amazônicos - NAEA, Programa de Pósgraduação em Desenvolvimento Sustentável do Trópico Úmido, 2008.

BAENA, Talita Cristina Araújo. Música e tecnointerações na Amazônia paraense: Retóricas e identificações culturais em materialidades do Terruá Pará e da banda de Thrash Metal Antcorpus. Belém-PA: UFPA, 2013. 97 p. Dissertação. (Mestrado em Ciências da Comunicação): Programa de Pós-graduação

Comunicação Cultura e Amazônia, 2013.

BHABHA, Homi. 0 local da cultura. Belo Horizonte: Editora da UFMG, 1998.

CARDOSO FILHO, Jorge. Poética da música underground: vestígios do heavy metal em Salvador. Rio de Janeiro: E-Papers, 2008.

CASTR0, Fábio Fonseca de. Entre o Mito e a

Fronteira. Belém: Labor Editorial, 2011.

COTA, Raymundo Garcia. Carajás: a invasão desarmada. 2. ed. Pará: Novo Tempo Comunicações, 2007. (Leitura Popular, 3).

FORTUNA, Carlos; SILVA, Augusto Santos. A cidade do lado da cultura: Espacialidades sociais e modalidades de intermediação social. In: SANTOS, Boaventura de Sousa (Org.). A globalização e as ciências sociais. São Paulo: Cortez, 2005.

GUMBRECHT, Hans Ulrich. Produção de presença: 0 que o sentido não consegue transmitir. Rio de Janeiro: Contraponto: Ed. PUC-Rio, 2010.

JANOTTI JÚNIOR, Jeder. Are you experienced?: experiência e mediatização nas cenas musicais.

Contemporânea - comunicação e cultura. Salvador, vol. 10, n. 01, p. 116-128, 2012.
; SÁ, Simone Pereira (Org.). Cenas Musicais.

Guararema, SP: Anadarco, 2013.

MARQUES, Ângela Cristina Salgueiro. Cenas de dissenso e a política das rupturas e fraturas na evidência do visível. In: BRASIL, André; MORETTIN, Eduardo; LISSOVSKY, Mauricio (Org.). Visualidades hoje. Salvador: EDUFBA; Brasília: Compós, 2013.

RANCIERÈ, Jacques. A partilha do sensível. São Paulo: Ed. 34, 2005.

SODRÉ, Muniz. As estratégias sensíveis. Petrópolis, RJ: Vozes, 2006.

WEINSTEIN, Deena. Heavy Metal: the music and its culture. United States: Da Capo, 2000. 
In the land of metal: aesthetic materialities and epiphanies of the heavy metal in the amazon frontier

\section{Abstract}

This paper introduces an analysis of the materialities of the thrash metal band Antcorpus. Vectorized by techno-interactions, we note that in such materialities there is the emergency of aesthetic epiphanies of Amazon borderer areas. These aesthetic epiphanies, on the other hand, shape a poetic of the dissent, in which are stated cultural and identity differences that contest an imagined Amazon, since the colonial period, such as "El Dorado" or "the green paradise". We conclude that, besides the evidence of cosmopolitism, the sonority of the heavy metal is linked to an aesthetic regime of identifications that offers possibilities of visuality to those on the frontier, in the margins, and that, because of this, they are made invisible in hegemonic and traditional modes of representation.

\section{Keywords}

Heavy Metal. Materialities. Visualities.

\section{En La Tierra Del Metal: materialidades e epifanías estéticas del heavy metal en una frontera amazónica}

\section{Resumen}

Este artículo trae el análisis de las materialidades de la banda de thrash metal Antcorpus. Vectorizadas por tecnointeracciones, se observa, en esas materialidades, la emergencia de epifanías estéticas en espacios de la frontera amazónica. Estas, por su vez, estructuran una poética de disidencia, en la cual son enunciadas diferencias culturales y de identidad, contestadoras de una Amazonia imaginada desde la época colonial como el "El dorado" o "el paraíso verde". Así, se concluye que, al mismo tiempo en que abarca evidencias del cosmopolitismo, el sonido del heavy metal está entrelazado a un sistema de identificación estética, que ofrece posibilidades de visualidades a aquellos que están en la frontera, a la orilla, y que, por esa razón, son invisibles en las formas hegemónicas y tradicionales de representación.

\section{Palabras-Clave}

Heavy metal. Materialidades. Visualidades. 


\section{Expediente}

A revista E-Compós é a publicação científica em formato eletrônico da Associação Nacional dos Programas de Pós-Graduação em Comunicação (Compós). Lançada em 2004, tem como principal finalidade difundir a produção acadêmica de pesquisadores da área de Comunicação, inseridos em instituições do Brasil e do exterior.

\section{E-COMPÓS I www.e-compos.org.br I E-ISSN 1808-2599}

Revista da Associação Nacional dos Programas

de Pós-Graduação em Comunicacão.

Brasília, v.17, n.2, mai./ago. 2014.

A identificação das edições, a partir de 2008

passa a ser volume anual com três números.

\section{CONSELHO EDITORIAL}

Afonso Albuquerque, Universidade Federal Fluminense, Brasil Alberto Carlos Augusto Klein, Universidade Estadual de Londrina, Brasil Alex Fernando Teixeira Primo, Universidade Federal do Rio Grande do Sul, Brasil Rio Grande do Sul, Brasi

Ana Gruszynski, Universidade Federal do Rio Grande do Sul, Brasil Ana Silvia Lopes Davi Médola, Universidade Estadual Paulista, Brasil André Luiz Martins Lemos, Universidade Federal da Bahia, Brasi Ângela Freire Prysthon, Universidade Federal de Pernambuco, Brasil Antônio Fausto Neto, Universidade do Vale do Rio dos Sinos, Brasil Antonio Carlos Hohlfeldt, Pontifícia Universidade Católica do Rio Grande do Sul, Brasil Antonio Roberto Chiachiri Filho, Faculdade Cásper Líbero, Brasi Arlindo Ribeiro Machado, Universidade de São Paulo, Brasil Arthur Autran Franco de Sá Neto, Universidade Federal de São Carlos, Brasil Benjamim Picado, Universidade Federal Fluminense, Brasil César Geraldo Guimarães, Universidade Federal de Minas Gerais, Brasil Cristiane Freitas Gutfreind, Pontifícia Universidade Católica do Rio Grande do Sul, Brasil Denilson Lopes, Universidade Federal do Rio de Janeiro, Brasil Denize Correa Araujo, Universidade Tuiuti do Paraná, Brasi Edilson Cazeloto, Universidade Paulista , Brasil

Eduardo Vicente, Universidade de São Paulo, Brasil Eneus Trindade, Universidade de São Paulo, Brasil Erick Felinto de Oliveira, Universidade do Estado do Rio de Janeiro, Brasi Florence Dravet, Universidade Católica de Brasília, Brasil Gelson Santana, Universidade Anhembi/Morumbi, Brasi Gilson Vieira Monteiro, Universidade Federal do Amazonas, Brasil Gislene da Silva, Universidade Federal de Santa Catarina, Brasil Guillermo Orozco Gómez, Universidad de Guadalajara Gustavo Daudt Fischer, Universidade do Vale do Rio dos Sinos, Brasil Hector Ospina, Universidad de Manizales, Colômbia Herom Vargas, Universidade Municipal de São Caetano do Sul, Brasil Ieda Tucherman, Universidade Federal do Rio de Janeiro, Brasil Inês Vitorino, Universidade Federal do Ceará, Brasil Janice Caiafa, Universidade Federal do Rio de Janeiro, Brasil Jay David Bolter, Georgia Institute of Technology Jeder Silveira Janotti Junior, Universidade Federal de Pernambuco, Brasi João Freire Filho, Universidade Federal do Rio de Janeiro, Brasil John DH Downing, University of Texas at Austin, Estados Unidos Ana Carolina Damboriarena Escosteguy, Pontifícia Universidade Católica do

José Afonso da Silva Junior, Universidade Federal de Pernambuco, Brasil José Carlos Rodrigues, Pontifícia Universidade Católica do Rio de Janeiro, Brasil José Luiz Aidar Prado, Pontifícia Universidade Católica de São Paulo, Brasil José Luiz Warren Jardim Gomes Braga, Universidade do Vale do Rio dos Sinos, Brasil Juremir Machado da Silva, Pontifícia Universidade Católica do Rio Grande do Sul, Brasil Laan Mendes Barros, Universidade Metodista de São Paulo, Brasil Lance Strate, Fordham University, USA, Estados Unidos Lorraine Leu, University of Bristol, Grã-Bretanha Lucia Leão, Pontifícia Universidade Católica de São Paulo, Brasil Luciana Panke, Universidade Federal do Paraná, Brasil Luiz Claudio Martino, Universidade de Brasília, Brasil Malena Segura Contrera, Universidade Paulista, Brasil Márcio de Vasconcellos Serelle, Pontifícia Universidade Católica de Minas Gerais, Brasil Maria Aparecida Baccega, Universidade de São Paulo e Escola Superior de Propaganda e Marketing, Brasil Maria das Graças Pinto Coelho, Universidade Federal do Rio Grande do Norte, Brasil Maria Immacolata Vassallo de Lopes, Universidade de São Paulo, Brasil Maria Luiza Martins de Mendonça, Universidade Federal de Goiás, Brasil Mauro de Souza Ventura, Universidade Estadual Paulista, Brasil Mauro Pereira Porto, Tulane University, Estados Unidos Nilda Aparecida Jacks, Universidade Federal do Rio Grande do Sul, Brasil Paulo Roberto Gibaldi Vaz, Universidade Federal do Rio de Janeiro, Brasil Potiguara Mendes Silveira Jr, Universidade Federal de Juiz de Fora, Brasil Renato Cordeiro Gomes, Pontifícia Universidade Católica do Rio de Janeiro, Brasil Robert K Logan, University of Toronto, Canadá

Ronaldo George Helal, Universidade do Estado do Rio de Janeiro, Brasil Rosana de Lima Soares, Universidade de São Paulo, Brasi Rose Melo Rocha, Escola Superior de Propaganda e Marketing, Brasil Rossana Reguillo, Instituto de Estudos Superiores do Ocidente, Mexico Rousiley Celi Moreira Maia, Universidade Federal de Minas Gerais, Brasi Sebastião Carlos de Morais Squirra, Universidade Metodista de São Paulo, Brasil Sebastião Guilherme Albano da Costa, Universidade Federal do Rio Grande do Norte, Brasil

Simone Maria Andrade Pereira de Sá, Universidade Federal Fluminense, Brasi Tiago Quiroga Fausto Neto, Universidade de Brasília, Brasil Suzete Venturelli, Universidade de Brasília, Brasil Valerio Fuenzalida Fernández, Puc-Chile, Chile Veneza Mayora Ronsini, Universidade Federal de Santa Maria, Brasil Vera Regina Veiga França, Universidade Federal de Minas Gerais, Brasil

\section{COMISSÃO EDITORIAL}

Cristiane Freitas Gutfreind I Pontifícia Universidade Católica do Rio Grande do Sul, Brasil Irene Machado I Universidade de São Paulo, Brasil

Jorge Cardoso Filho I Universidade Federal do Reconcavo da Bahia, Brasil / Universidade Federal da Bahia, Brasil

CONSULTORES AD HOC

Adriana Amaral, Universidade do Vale do Rio dos Sinos, Brasil

Alexandre Rocha da Silva, Universidade Federal do Rio Grande do Sul, Brasi Arthur Ituassu, Pontifícia Universidade Católica do Rio de Janeiro, Brasil Bruno Souza Leal, Universidade Federal de Minas Gerais, Brasil Elizabeth Bastos Duarte, Universidade Federal de Santa Maria, Brasil Francisco Paulo Jamil Marques, Universidade Federal do Ceará, Brasi Maurício Lissovsky, Universidade Federal do Rio de Janeiro, Brasil Suzana Kilpp, Universidade do Vale do Rio dos Sinos, Brasil Vander Casaqui, Escola Superior de Propaganda e Marketing, Brasil

EDIÇÃO DE TEXTO E RESUMOS I Susane Barros SECRETÁRIA EXECUTIVA I Helena Stigger EDITORAÇÃo ELETRÔNICA I Roka Estúdio
COMPÓS I www.compos.org.br

Associação Nacional dos Programas de Pós-Graduação em Comunicação

Presidente

Eduardo Morettin

Universidade de São Paulo, Brasil

eduardomorettin@usp.br

Vice-presidente

Inês Vitorino

Universidade Federal do Ceará, Brasil

ines@ufc.br

Secretária-Geral

Gislene da Silva

Universidade Federal de Santa Catarina, Brasil

gislenedasilva@gmail.com 